\title{
Teaching Study of Marine Diesel Engine Based on O-PIPAS Teaching Method
}

\author{
Xu Wensheng \\ Tianjin maritime college \\ Tianjin China
}

\begin{abstract}
The purpose of this paper is to improve the teaching effect of marine diesel engine course by using informational teaching. The method is to analyze teaching methods, analyze the advantages and disadvantages of MOOC teaching methods, analyze the advantages and disadvantages of SPOC teaching methods, compare and analyze the limitations of B-learning teaching methods and blended learning methods, and combine the contents and characteristics of marine diesel courses And requirements, put forward the use of O-PIPAS teaching method for marine diesel engine teaching. Results show that the method is effective and feasible. Innovation is the use O-PIPAS teaching design and verification.
\end{abstract}

Keywords-MOOC; SPOC; B-learning; Flipped Classroom; OPIPAS; Marine diesel engine course

\section{INTRODUCTION}

The advent of information technology, has greatly improved the quality and speed of information transmission, so that the function of information processing far surpassed mankind's own ability to achieve the integration and automation of information storage, transmission, processing and utilization, thus creating a brand new the information age. The advent of the information age not only extends people's brain functions and expands human intelligence, which greatly enhances human's ability to understand the world and transform the world. It also extensively permeates and affects various fields of human society. In the field of education, great changes have taken place from the educational concept to all aspects of the educational process. In the field of learning, information technology has also played a significant role in transformation. Education is the central part of the real society. Education is also greatly influenced by the advent of big data and the excavation of educational data, which provides support for improving teaching management and teaching quality. US schools are able to predict student enrollment rates with $85 \%$ accuracy through student data analysis [1]. Information technology and education teaching how to achieve in-depth integration effectively, 2017 associate professor Guo Jianpeng at Xiamen University, Put forward the "O-PIPAS teaching method" in information technology and education teaching. That is MOOC + SPOC + Big Data + Flip Class + Mix learning method of multi-way integration.

\section{TEACHING Method ANALysis}

MOOC does not use video recording in the classroom, as it naturally excludes online learners from the atmosphere, and lectures, rhythms, and methods are also offline. MOOC adjusts teaching content (usually for greater popularity), controls rhythm (short video, about 2 hours a week) for online learners, emphasizing expressiveness and affinity (more beautiful pictures, more visuals, Teachers are more face-to-face) Video Lessons are not the only lecture format. Rich text, Flash, HTML5 can all produce MOOC courseware. Most importantly, MOOC places emphasis on interaction during the course. Common forms include video embedded test questions, follow the discussion of courseware, virtual experiment bench and so on. This is a lot better than a one-way video lectures because learners are not passively accepted, but are able to engage and get feedback. Large-scale, online, open is a notable feature of MOOC. As a new learning and teaching method, MOOC is easy to use; it is low in cost; most MOOCs are free; it covers a large population; learns independently; and learning resources are abundant. The traditional teaching requires teachers and students together in space and time, which requires time cost and capital cost. As a form of distance learning [2], MOOC is a characteristic of time and space separation. It is low cost and conducive to individualized learning, coupled with its rich and open learning resources, as learners will undoubtedly be willing to embrace, and join them, but the popularity of famous universities soaring, weak schools were ruthlessly eliminated, school education has its own unique cultural characteristics, and material and system the spirit of the form shown. Campus culture can imperceptibly give students cultural infiltration, culture, which is unmatched by MOOC. And the number of learners in a course of MOOC is relatively large, it is almost impossible for both teachers and students to interact with each other. Therefore, it is inevitable for teachers and students to exchange and answer questions, continuous teaching in traditional teaching, the chances of each student to communicate with the teacher are shared. The overall teaching atmosphere still can not achieve the effect of the traditional school. Students need education, education should be comprehensive, and students need not only knowledge of the curriculum, but also the needs of expanding contacts, trying to live independently, participating in community activities, social experiences and so on. MOOC is too easy to cheat, which is also a common problem of online education [3]. In the MOOC classroom, it is impossible to carry out a comprehensive 
analysis of learner characteristics, and there may be situations where excellent students are not encouraged to pay attention and may also be buried.

Small Private Online Course) is first proposed and used by Professor Armand fox of the University of California, Berkeley. With MOOC giving teachers a chance to serve the world and make a name for themselves in professional fields, SPOC allows teachers to return to school more often and return to small online classes. Before class, teachers are learners and integrators of course resources. They do not have to be the protagonist in the lecture video, nor do they have to prepare for each class's lectures, but be able to integrate a variety of online and physical resources according to student needs. In the classroom, teachers are mentors and promoters. They organize student group discussions and provide them with individualized guidance at any time to jointly solve the problems they encounter. SPOC has innovated the classroom teaching mode, aroused teachers' teaching enthusiasm and classroom vitality [4].

SPOC greater emphasis on students complete, in-depth learning experience that will help improve the completion rate course, by defining access conditions and the size of the student curriculum, SPOC can customize programs for these students specially selected to provide them with a difference, the intensity greater professional support can enhance students' complete curriculum experience, thereby avoiding MOOC high dropout rates and low completion rates, making certificate acquisition easier. SPOC experiments further show that compared to traditional classroom, MOOC video SPOC use of careful preparation designated reading material more attractive to students than to stimulate their participation, for those students who lack motivation, in particular. Compared with pure MOOC, SPOC makes online learning go beyond the stage of copying classrooms, resulting in more effective learning.

Flipped classroom, we mean reorienting time inside and outside the classroom to transfer the power of decision making from the teacher to the student. In this model of teaching, the valuable time in class allows students to focus more on proactive, project-based learning, working together to address the challenges of localization or globalization, and other real world issues to gain deeper understanding. Teachers no longer occupy the classroom time to teach information that requires students to complete autonomous learning prior to class, they can watch video lectures, listen to podcasts, read enhanced ebooks, talk with other classmates on the web, check the materials you need at any time. Teachers also have more time to communicate with everyone. After the class, students autonomously plan their learning content, learning the rhythm, style, and presentation of knowledge. Teachers use lecture and collaboration methods to meet the needs of students and facilitate their personalized learning. The goal is for students to gain practical experience more real learning. Flipped classroom mode is part of a larger education campaign that overlaps with blended learning, inquiry learning, and other pedagogies and tools in a way that makes learning more flexible and proactive and empowers students to engage more. In the internet age, students learning rich online courses via the Internet do not necessarily have to go to school for teachers. The internet, especially the mobile Internet, has given birth to the flip classroom, teaching mode. Flip classroom style is a complete subversion of the traditional classroom teaching structure and teaching process based on typography, which will lead to a series of changes in the role of teachers, course mode, management mode and so on. Although turning over the control of learning to students, we should see the current situation of domestic students: not good at asking questions and being less active. These two factors have a direct impact on the effect of turning over the classroom. From the teacher's point of view, domestic teachers have to guide the learning of professional quality? Flip classroom is very important point is to check the effectiveness of student learning through teacher guidance and Q \& A[5], in the flip class, the role of the teacher is not actually played down, but from another side has been strengthened, it requires teachers to pass Set questions, through the discussion between students and the completion of homework, the project situation to analyze and grasp the effect of student learning, compared to the traditional teaching mode, the teacher from active to passive, change from dominant to guide, which for their occupation quality has higher requirements, and as students who are accustomed to the traditional education model teacher groups, it is difficult to complete their transformation in a short time.

B-learning is the development of educational technology, traditional classrooms are gradually being replaced by blended learning methods. Through the use of high-tech equipment such as computers, students of different grades can be accommodated in the same classroom and used the previous knowledge and learning styles to match equipment, tools, technology, media, and teaching materials, according to their own learning schedule. The initial preparatory steps allow trainees to understand basic skills and general framework and help trainees improve their learning skills so as to help trainees to proceed smoothly to the next step. Tell me, show me, let me, check me, support me, connect me, they are currently used in corporate training.

\section{MARINE DIESEl ENGINEO-PIPAS TEACHING}

Marine diesel engine courses is a combination of theoretical knowledge and practice. Its teaching aims to cultivate students practical abilities, create abilities, make the best of the best and bypass them in order to promote the coordinated development of students' knowledge, abilities and qualities. Students are essential for the organic combination of mechanical drawing, mechanism and mechanical transmission, marine engineering materials, marine diesel engine, ship power plant and maintenance and repair of ship parts.

This course is the major specialized course of engineering major in marine engineering and the main course, and also the compulsory subject for obtaining certificate of competency of marine engineers appointed by the maritime safety administration of the People's Republic of China. Through the learning of diesel courses, students can acquire the basic knowledge of diesel engines and practical operation and maintenance skills. They are also entitled to manage diesel engines on duty and comply with the international convention on standards of training, certification and watch keeping for seafarers 1978 and 2010 manila amendment requirements [4] 
Teaching objectives and requirements: To understand the working principle of diesel engines, to be familiar with the structure and main components of typical diesel engines, to master the routine operation, management and maintenance methods of diesel engines, to master the composition and function of each system of diesel engines and the operating principle and adjustment method of each system component .And the main factors that affect the running performance of the diesel engine, and can judge the working condition of the diesel engine according to the running phenomenon, and deal with the common faults skillfully and accurately.

This course mainly introduces the working principle, parts structure, performance index[5], operating characteristics, measurement and analysis of dynamometer, supercharging technology, speed regulation, start-up, commutation and maneuvering of diesel engine, combustion, lubrication and cooling, vibration and elimination of diesel engine devices, and operation and management. Based on the modern large-scale marine low-speed two-stroke diesel engine and medium-speed diesel engine as the main models, the paper introduces the use, adjustment, maintenance, as well as common faults and handling. The general idea of course teaching design as shown in Figure 1.

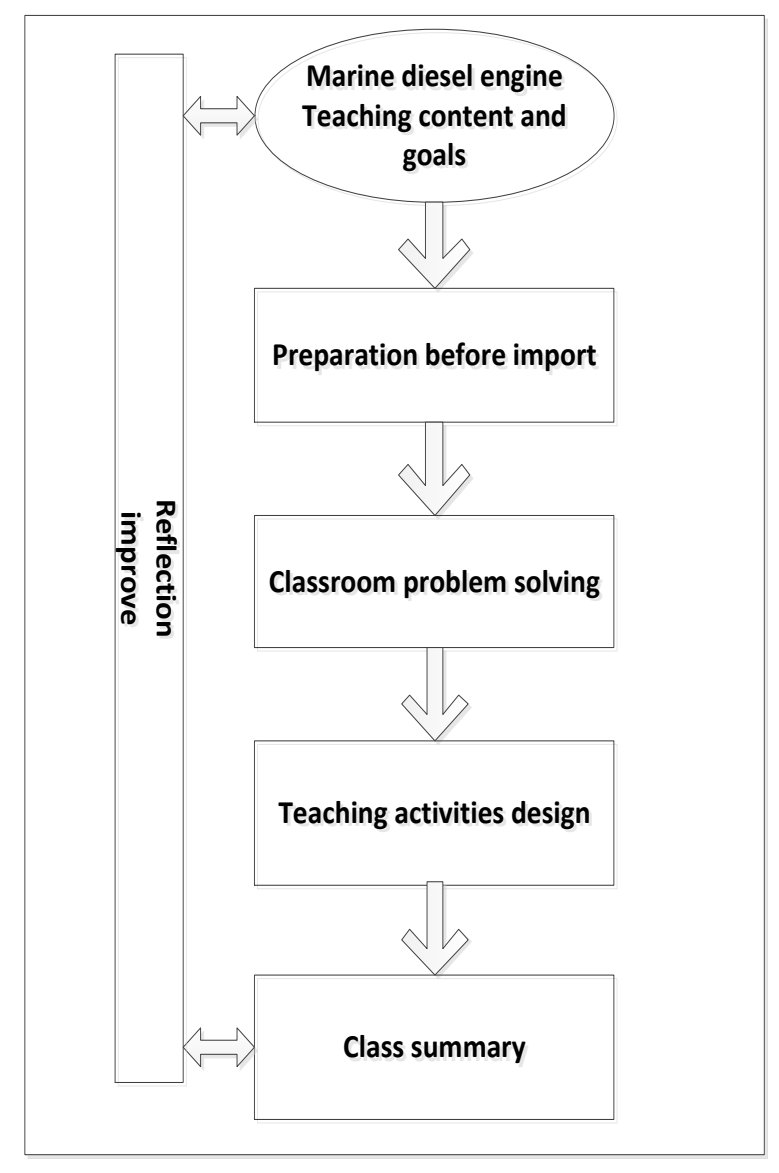

Fig. 1. Marine diesel engine teaching design

Marine diesel engine courses include marine four-stroke diesel engine, the basic concept of diesel engine, four-stroke diesel engine working principle. Features of wärtsilä 32, medium speed diesel engine, medium speed diesel engine features, main moving parts of four-stroke diesel engine, main fasteners of four-stroke diesel engine, assembly of four-stroke diesel engine, installation of four-stroke diesel engine for marine etc. Working principle of two-stroke diesel engine, stroke diesel main moving parts, two-stroke diesel main fasteners, marine two-stroke diesel installation inspection data requirements, diesel fuel system, diesel engine oil system, diesel engine cooling system, diesel engine starting system, diesel engine exhaust system. formation and combustion of diesel combustible gas, formation and combustion of mixture, injection and fogging of fuel, optimization of combustion process, process and influencing factors of diesel engine, starter commutation and speed regulation system, diesel governor system, diesel governor common cause, diesel engine can not start fault, diesel engine power failure, exhaust smoke color is not normal troubleshooting methods. MAN MC \& ME series of electronically controlled diesel engines, Wartsila RTflex low-speed diesel marine electronic control common rail technology system, [6] electronic control diesel engine common faults. Disassembly and disassembly of diesel moving parts, fuel injection equipment disassembly and assembly, check and adjustment of valve clearance, injection timing check and adjustment, supercharger overhaul etc.

Based on O-PIPAS teaching, the piston diesel engine course teaching process, the first use of multimedia courseware, explained in detail the role of piston, piston working conditions, piston requirements and materials, the role of connecting rod, connecting rod working conditions, connecting rod requirements and Materials, multimedia courseware vivid presentation, students through the measurement of threedimensional drawing of the piston, a strong stimulus to the students' perceptions, practical operation, theoretical penetration. Piston connecting rod mechanism, force conditions, analysis of piston gas, force inertial force friction and resultant, analysis of four-stroke connecting rod subject to alternating tension and pressure, the two-stroke connecting rod is always subject to pressure questions, step by step press [7]: thinking source in doubt, questions can arouse students' awareness conflicts, guide students to open the gate of thinking, take the initiative to seek answers. For example, why high-speed fourstroke diesel engine piston is aluminum alloy, large two-stroke diesel engine is the choice of cast iron and steel? The difference between the big end of the connecting rod and the big end of the ship? The purpose of cleaning, the carbon deposits and shoulders. When the piston is disassembled? By proposing various practical problems, we can strengthen students 'thinking, mobilize students' thinking, cultivate innovative thinking, cultivate happy thinking, and promote teaching. Practice, through the diesel engine piston assembly system to explain and a complete demonstration, students in the lively teaching process mastered the basic knowledge, and through observation in the mind established a diesel engine piston assembly system. Well, the process of practice is not only a process of deepening understanding, but also a process of achieving proficiency in teaching. Comment, practice, ask each group of students to discuss, through debates to solve the problem and consolidate the purpose of knowledge. Then each group made a concluding statement by the team leader to 
summarize the disassembly process of the group and find out the problems that existed in the disassembly process. Finally, teachers conduct a comprehensive evaluation of the universality issue and find out the best solution to the problem. Re-practice, amend the first practice of misconceptions and misconduct, consolidation of knowledge, to achieve proficiency in the purpose.

\section{CONCLUSION}

Realizing the teaching contents and goals of marine diesel engine, pre-class preparation and introduction, pre-class teaching video, classroom problem solving, classroom activities design, classroom summary, reflection, integration complete the closed-loop teaching process. The O-PIPAS teaching method is used to teach marine diesel engine. The practice proves that the method can enhance students' interest and is effective and feasible. I believe that in the future development of higher education, big data will always exert a tremendous influence on the innovation and development of education. For the improvement of education quality, popularity, personalized learning, provide support.

\section{ACKNOWLEDGMENT}

This work was financially supported by 2016 higher vocational and technical education research association of Tianjin, research on the effectiveness and evaluation of ship security consciousness and responsibility course based on cloud computing (Grant No. XVI130).

\section{REFERENCES}

[1] DAI Shu-Long, LIU Shu-Ping, SUN Jian, DU Lin-Hai, GONG YuGuang.Global Data Platform for International Maritime Education and Training Based on Information Sharing [J]. Maritime Education Research, 2017,34 (01): 15-19. (In Chinese)

[2] Fan miaoran. MOOC China's research hot spots and development trend analysis [J]. Modern Education Technology, 2017,27 (03): 34-40. (In Chinese)

[3] Yang Fang, Zhang Huanrui, Zhang Wenxia.Study on MOIX and Rain Classroom Teaching - A Case Study of MOOC and Rain Class [J]. Modern Education Technology, 2017,27 (05) ): 33-39. (In Chinese)

[4] Lu Haiyan.Design of College English Curriculum Based on "Creativity Education + SPOC" Mode [J]. Modern Educational Technology, 2017,27 (03): 93-98. (In Chinese)

[5] ZOU Chun-ming, WEN Yuan-qiao.Reflections on the Development of Maritime Education in Research-oriented Universities [J]. Marine Education Research, 2016,33 (01): 1-5. (In Chinese)

[6] ZHANG Rong-xuan. Influential Factors and Educational Strategies on the Stability of Maritime Professional Thoughts [J]. Marine Education Research, 2017,34 (02): 107-109. (In Chinese)

[7] Wen Yuanquan.Strategic Reflection on the Training of New Engineering and Talents in Navigation [J]. Marine Education Research, 2017,34 (03): 10-14. (In Chinese)

[8] DING Cui-hong.Study on Multi-dimensional Interactive SPOC Teaching Mode [J]. Modern Education Technology, 2017, 27 (07): 102108. (In Chinese) 